\title{
Papéis da imprensa na formação das identidades nacionais ${ }^{1}$
}

\author{
Roles of the press in the formation of national identities
}

\author{
Anne-Marie Thiesse ${ }^{\circledR}(\mathbb{C}$
}

\section{Tradutores: Weslei Estradiote Rodrigues ${ }^{\mathrm{b}} \odot$ e Pedro Giovanetti Cesar Pires ${ }^{c}$}

Ao final do século XIX, o hebraico era uma língua religiosa que permitia a alguém se dirigir a Deus, mas não a seu vizinho para discutir com ele os assuntos habituais, muito menos para cortejar sua vizinha. A criação do hebraico moderno, destinado a se tornar a língua profana da nação judaica em formação, implicou um considerável trabalho filológico ao qual se dedicou Eliezer Ben Yehuda (18581923) (Diecкhoff, 1993, p. 123-155). Mas, por mais elaborado que fosse o trabalho semântico e sintático, o hebraico moderno, para se tornar uma língua viva, tinha necessidade de falantes e escritores. Como tornar uma criação linguística de eruditos em um genuíno suporte de comunicação? Como transformar o artifício (literalmente) em língua natural? Como convencer os indivíduos praticantes de uma ou, frequentemente, várias línguas a adotar uma nova, inicialmente de uso muito limitado e sem outro interesse que não fosse o político-ideológico?

A tarefa poderia parecer das mais árduas, mas em muito pouco tempo o hebraico moderno se tornou a verdadeira língua de comunicação de uma nação, desenvolvendo simultaneamente sua cultura e suas reivindicações políticas. Escolas oferecendo o ensino sistemático do hebraico moderno foram criadas na Palestina por militantes convertidos e prosélitos; mas a imprensa teve também um papel importante na difusão do conhecimento do hebraico moderno entre as populações judaicas da Europa Oriental (KARNIEL, 1987, p.249-252).

O folhetim, suspeitamos, não foi o último argumento destinado a atrair leitores e leitoras. Verdadeiramente, o hebraico moderno competiu com outra língua pelo título de língua nacional judaica. A situação do ídiche era inicialmente oposta

1 Originalmente publicado em: Thiesse, Anne-Marie. "Rôles de la presse dans la formation des identités nationales”. In: VAILlant, Alain; Thérenty, Marie-Ėve (Orgs.). Presse, nations et mondialisation au XIXe siècle. Paris: Nouveau Monde, 2010. Agradecemos imensamente à autora pela gentil autorização para tradução e publicação do texto em português.

a Anne-Marie Thiesse é Diretora de Pesquisa do CNRS, França. e-mail: athiesse@ens.fr

b Weslei Rodrigues é doutorando em sociologia na USP e membro do Núcleo de Sociologia da Cultura. e-mail: weslei.estradiote@gmail.com

c Pedro Pires é doutor em sociologia pela USP e Master no Lateinamerika-Institut da Freie Universität zu Berlin na Alemanha.e-mail: pedrogiocesarpires@gmail.com 
àquela do hebraico: língua comunitária, ela não carecia de falantes, mas de prestígio. No final do século XIX, paralelamente à modernização/secularização do hebraico, operou-se um considerável trabalho de valorização/enriquecimento do ídiche para fazê-lo passar do estatuto de dialeto oral com variantes locais àquele de língua genuína, na qual poderiam ser redigidos todos os tipos de escritos, inclusive os de nível mais elevado. E então, novamente a imprensa, por suas diversas rubricas e folhetins, desempenhou um papel importante na codificação da língua, no enriquecimento de seu status e na constituição de um patrimônio de textos valorizados (RobIn, 1984). A entrada do ídiche na cena literária se fez pela publicação de Dos Klein Menchele, de Mendele Mokher Seforim, que surgiu em 1864 sob a forma de folhetim em Kol Mevasser, suplemento em ídiche do jornal hebraico de Odessa, Hamelitz. Como sublinha Jean Baumgarten:

A maior parte dos escritores ídiches dos séculos XIX-XX participaram diretamente da renovação da imprensa enquanto jornalistas, repórteres, folhetinistas ou diretores, contribuindo para formar uma nova imagem do intelectual judeu, engajado no combate, na análise política, e intermediário privilegiado entre os criadores e as massas judaicas. (...) Do ponto de vista da imprensa, a língua ídiche moderna pôde se afirmar, ganhar prestígio e ultrapassar o círculo restrito dos seus defensores. Tanto é assim que a distinção entre jornalista, folhetinista e escritor permaneceu obscura conforme essas diversas atividades se confundiam. A imprensa assumiu uma importância crescente na vida cotidiana dos Judeus. A leitura do jornal se torna um gesto social e identitário essencial: a imprensa vai preparar o terreno das transformações políticas, servir de laço social entre os membros das comunidades e incitar os Judeus a assumir novas responsabilidades (BAUMGARTEN, 1990, p.114-115).

De fato, os dois casos citados não são únicos na Europa do século XIX. Um número considerável de línguas nacionais foi construído a partir de línguas escritas mais ou menos obsoletas, mais ou menos confinadas a usos administrativos ou religiosos, ou a partir de dialetos, ou ainda a partir de combinações entre antigas línguas escritas e dialetos. Em todos os casos se colocou o problema da passagem entre a criação de gabinete e a real prática comunitária. A imprensa foi um dos instrumentos privilegiados de propaganda da nova língua. A "(re)nascença” da língua nacional é, ademais, frequentemente associada à criação de um periódico que a utilize. 
Assim, por exemplo, a criação em 1862 do hebdomadário Petersburgas Avizes foi considerada como o começo da língua letã moderna. Como o nome indica, o periódico foi fundado em São Petersburgo por patriotas letões germanófonos e russófonos. Mais uma vez, uma configuração frequente na qual é lançado "no estrangeiro" um periódico nacional(ista) por jovens que propagam a língua nacional ao mesmo tempo em que treinam usá-la e a refinam. A língua eslovena moderna toma impulso em 1843 com a fundação do jornal Kmetijske in rodelske novice (As notícias camponesas e industriais). Um intenso trabalho prático e teórico de elaboração da língua foi efetuado nesse jornal, criado em um momento em que as disputas pela determinação da língua eram virulentas nos meios letrados patriotas (três dialetos bem diferentes estavam presentes, então era igualmente necessário determinar a grafia a ser utilizada). Além disso, o jornal não hesita em apresentar a seus leitores os debates sobre a formação da língua: assim, em 1848, trata-se de encontrar uma palavra eslovena para transcrever a palavra "constituição" (BERNARD, 1998, p.63).

A imprensa, nesses empreendimentos de propagação linguística, vai de par com o livro, mas ela tem sobre ele sérias vantagens. O jornal deve abordar simultaneamente uma ampla gama de registros, nomear e comentar as realidades contemporâneas, tocar um público social e economicamente cada vez mais diversificado. Ele possui também as vantagens da continuidade temporal e da produção coletiva de textos: o que não é nada trivial quando o idioma ainda não possui um padrão fixo e quando existem problemas de todos os tipos com relação à sua determinação, particularmente gráfica. Em muitos casos, o alfabeto e a ortografia das línguas nacionais modernas foram progressivamente determinados, não pelas autoridades oficiais, mas pelas redações de jornais.

\section{IMPRENSA E IMAGINED COMMUNITY²}

A imprensa, certamente, não é somente um laboratório filológico e um suporte de difusão da língua nacional, ela é também um instrumento importante na criação de uma consciência nacional. Para as nações “emergentes” desprovidas de qualquer espécie de reconhecimento como Estados, a imprensa constitui, de algum modo, o verdadeiro território nacional. Ela é o único espaço em que a nação existe porque é dita, descrita, porque ela é objeto de debates e de aspirações apaixonadas. De modo mais geral, a imprensa é o lugar por excelência em que o "espaço público",

2 A menção à noção é feita em inglês no original, tal como foi mantido aqui (N. de T.). 
concepção característica da modernidade nacional, pode tomar forma e começar a se estruturar.

Para explicitar as relações particulares entre imprensa e nação no século XIX, eu proponho aqui retornar à definição da nação moderna apresentada por Benedict Anderson em sua célebre obra de 1983 Imagined Communities, Reflection on The Origin and Spread of Nationalism. Anderson, pioneiro das teorias atuais do fenômeno nacional, se inscreve em uma perspectiva construtivista e rompe com a concepção comum que vê as nações como entidades formadas em um período extremamente longo de tempo (essa concepção da nação como produto de uma história multissecular foi, de fato, elaborada e difundida pela historiografia a partir do século XIX).

Segundo Anderson, a nação moderna é resultado de uma tripla ruptura ideológico cultural nas concepções do homem e do universo. A primeira ruptura, segundo ele, recusa a ideia de que uma linguagem escrita particular oferece um acesso específico à verdade ontológica porque ela é parte integrante dessa verdade; essa ideia foi fundadora das grandes solidariedades religiosas. A segunda ideia contestada é a convicção de que a sociedade é naturalmente organizada hierarquicamente e dominada por monarcas que governam sob determinação divina. A terceira ideia refutada é uma concepção da temporalidade na qual cosmologia e história se confundem. A revolução da modernidade, segundo Anderson, consiste em uma nova maneira de associar os laços inter-humanos, o poder e o tempo. A nação moderna, portanto, é soberana, como formula a Declaração dos Direitos do Homem de 1789, contrária ao princípio da monarquia dinástica de direito divino. É uma comunidade concebida como fraternidade profunda, horizontal entre seus membros definidos como iguais a despeito de suas diferenças sociais. Mas é também uma imagined community, imaginada e imagética ${ }^{3}$ : mesmo os membros da menor nação jamais conhecerão todos os seus concidadãos e, portanto, no espírito de cada um vive a imagem de sua comunhão - secular.

Portanto, a nação moderna convoca uma dupla representação: uma propriamente política, pela qual o exercício da soberania é delegado à assembleias de representantes da nação, mas também a que coloca em imagens e em escritos a forma, os contornos, as particularidades, o patrimônio da nação, que permite aos seus componentes se conhecerem e conhecerem a sua unidade. Não nos deteremos aqui sobre todo o processo de criação e difusão das culturas nacionais

3 No original, a autora aponta um jogo de palavras em francês, associando as palavras "imaginée et imagée" (N. de T.). 
que se inicia no século XIX paralelamente à afirmação propriamente política do princípio nacional (Thiesse, 1999). Os outros textos deste volume ${ }^{4}$ precisam o papel eminente exercido pela imprensa na representação e ilustração (em todos os sentidos do termo) das “comunidades imaginadas". Ademais, a imprensa retrata a comunidade de pertencimento do leitor, mas no seio de um conjunto mais amplo: passa pela imprensa o conhecimento deste dado fundamental da era nacional, a saber, a coexistência de comunidades nacionais, ao mesmo tempo distintas, rivais e homólogas.

Mas se deve também sublinhar um elemento extensamente desenvolvido por Anderson e que interessa nossa coletânea especialmente. Segundo Anderson, duas formas forneceram, de maneira privilegiada, os meios técnicos de "representar" o gênero de comunidade imaginada que é a nação moderna, e eles são o romance e a imprensa ${ }^{5}$. A era dos "despertares nacionais", o século XIX, é, como sabemos bem, um período de formidável expansão do romance e da imprensa. A concomitância não é fortuita.

Para Anderson, o desenvolvimento da nação moderna, do romance e da imprensa participam de uma mesma revolução mental: a da concepção do tempo. Anderson opõe a simultaneidade de tipo messiânico - em que passado e futuro podem se fundir em um presente instantâneo - a uma simultaneidade que poderíamos chamar de secular e racional, da modernidade. A simultaneidade é a partir de então percebida como transversal, intertemporal: o que exprime a forma romanesca “enquanto isso". Ela não é marcada pela prefiguração e realização, mas pela coincidência temporal: é, segundo Anderson, uma simultaneidade que se mede pelo relógio e pelo calendário. Como exemplo, Anderson evoca a estrutura do romance balzaquiano, onde são apresentadas personagens diferentes, que não se conhecem entre si, mas são mostradas realizando suas ações à mesma hora do calendário.

Para resumir e trazer para nossas preocupações as proposições de Anderson, poderíamos dizer que nação, imprensa e romance modernos participam de uma mesma renovação das concepções da diegese. Renovação paralela àquela que afeta as concepções de autoridade (política e autoral) e de representação (política e literária). La Nation, Le Temps, The Times, die Zeit, El Tiempo: estes são títulos

4 Vaillant, Alain; ThéRenty, Marie-Ève (Orgs.). Presse, nations et mondialisation au XIXe siècle. Paris: Nouveau Monde, 2010.

5 "Why this transformation should be so important for the birth of the imagined community of the nation can best be seen if we consider the basic structures of two forms of imagining which first flowered in Europe in the eighteenth century: the novel and the newspaper. For these forms provided the technical means for 're-presenting' the kind of imagined community that is the nation" (ANDERSON, 1983, p. 24-25). 
de jornais que se encontram frequentemente pelo mundo, a partir do século XIX, e que, de uma certa forma, remetem à mesma concepção de espaço público.

Mas a relação metonímica entre imprensa e nação, prossegue Anderson, se dá em um outro nível, ligada a outros cofatores e coprodutos da modernidade: o mercado capitalista e a produção industrial. O livro, lembra Anderson, foi desde a invenção da imprensa a primeira mercadoria industrial produzida em série. A imprensa, por sua vez, é provavelmente o primeiro produto de massa concebido em termos de obsolescência imediata (para não dizer descartável). A leitura cotidiana do jornal apresenta, portanto, características notáveis quanto ao regime moderno de relações entre vida privada/vida pública ${ }^{6}$, indivíduo/comunidade nacional:

- A leitura é silenciosa, privada, mas cada leitor sabe que simultaneamente milhares de leitores a praticam igualmente. Ele pode eventualmente ver alguns deles ao seu entorno.

- A leitura do jornal é repetida sem cessar, a intervalos regulares, numa temporalidade homogênea. $\mathrm{O}$ que permite ver nela uma forma de cerimônia de massa, a forma secular, para o homem moderno, da oração matinal segundo a fórmula de Hegel.

Porque ele é uma forma ao mesmo tempo privada e coletiva, ritual e secular, o consumo do jornal possui uma relação de homologia com o pertencimento à comunidade nacional. Não é por acaso que abundam nos livros do século XIX, mas também na imprensa, descrições dos leitores de jornais, indivíduos inclinados sobre as folhas, indiferentes a seus congêneres, mas formando um vasto conjunto absorvendo o mesmo texto: essas mônadas na multidão são frequentemente vistas como figuração da opinião pública... e do perigo democrático. A imprensa era ainda marginalmente consumida pelas classes populares e já se multiplicavam as denúncias horrorizadas do seu poder manipulador. A imprensa é acusada recorrentemente de penetrar os espíritos, do castelo ao casebre mais humilde, em suma, de constituir uma comunidade nacional - por princípio transsocial. Lembremo-nos do famoso discurso de Chapuys-Montlaville na câmara dos deputados em 1845: "A imprensa, esse poder duvidoso, manifestação da vida nacional, esse poder que dá luz a todos os outros poderes, que criou neste país uma história e uma sociedade novas" (Chapuys-Montlaville apud QuéfFelec, 2000).

6 "A esfera pública burguesa pode, antes de tudo, ser compreendida como a esfera de pessoas privadas reunidas em público" (HABERMAS, 1978). 
A essas acusações precoces e indefinidamente repetidas de forjar a opinião pública, os profissionais da imprensa respondem, novamente de forma precoce e consistente, afirmando um outro projeto: o de educar a população, ao divulgar amplamente os conhecimentos e elevando o gosto das massas. Mas essa reivindicação de uma função pedagógica destinada ao grande público não faz sentido a não ser, justamente, na era nacional. Ela seria desprovida de sustentação nos séculos precedentes. Na era pré-nacional, a única instrução comum que parecia necessária era a de ordem religiosa; de resto, os diferentes grupos sociais e locais ressaltavam culturas diferenciadas e modos de formação específicos. Como sublinhou o antropólogo Ernest Gellner (1983), a era nacional, porque corresponde notavelmente a transformações maiores nos modos de produção e de troca, mas também na organização social, coloca a exigência de uma instrução homogeneizada, secular, na qual a base é comum aos diferentes grupos sociais. E porque o livro permanece no século XIX uma forma material associada à alta cultura, a imprensa pôde pretender o papel de elevador pelo qual as classes baixas ascenderiam à cultura comum.

\section{A APREENSÃO GRÁFICA DO MUNDO}

A imprensa participa também, lembremos, da grande transformação que, na era nacional, afeta a percepção do espaço. A multiplicação de relógios, que inscrevem os indivíduos em uma temporalidade homogênea, vai ao encontro com aquela dos mapas e itinerários transcritos em unidades de medida homogêneas (não nos esqueçamos que a Revolução Francesa não somente proclamou a soberania da nação e a abolição dos privilégios de nascença, mas também reorganizou o espaço nacional em unidades declaradas iguais... e implantou o princípio de um sistema universal de pesos e medidas). Porque é fundado sobre uma formatação em rubricas - ao mesmo tempo hierarquizada, claramente delimitada e submetida à repetição, o espaço do jornal registra e difunde amplamente a nova apreensão do mundo no qual se inscreve o indivíduo. Nós somos habituados a viver e a nos mover em territórios balizados por pontos de referência e sinalização padronizados que nos dão sistematicamente o domínio gráfico; nós medimos com dificuldade o abismo que nos separa de um universo em que a diferença essencial se dava entre o espaço físico conhecido e todo o restante, cuja apreensão era irredutível a uma medida comum. De um universo em que, para a grande massa, existiam de um lado os saberes de aquisição local e, do outro, o conjunto não ordenado, não informado, de ditos vindos dos viajantes. A imprensa do século XIX familiariza com o desconhecido, transforma a ruptura inicial em continuidade homogênea e organizada. 
A imprensa participou, portanto, da construção das identidades nacionais não somente difundindo o novo saber sobre a nação, mas forjando também, ao nível antropológico, as próprias estruturas de apreensão do fato nacional. Ela também exerceu um papel ao nível infranacional, quer dizer, aquele da articulação entre a unidade nacional e a diversidade do território. $\mathrm{O}$ processo de construção das culturas nacionais, com efeito, não substituiu a miríade de particularismos anteriores por uma uniformidade absoluta. A diversidade foi mantida, mas foi em grande parte simplificada e sobretudo inserida em um organograma submetendo-a hierarquicamente à unidade nacional.

As modernas culturas regionais não são vestígios da era pré-nacional, mas verdadeiramente coprodutos da construção das identidades nacionais. As identidades regionais foram elaboradas em relação às identidades nacionais, da qual elas deveriam, idealmente, ser variantes harmoniosamente derivadas. Segundo a fórmula, muitas vezes repetida, o mosaico de pequenas pátrias forma o alicerce e a riqueza da grande pátria comum. Essa formulação de diversidades territoriais complementares e unidas apresentava a imensa vantagem de fornecer uma representação metonímica - perfeitamente pacífica - da diversidade social no seio da nação. Eis porque a fase crucial das construções nacionais, a saber, a integração decisiva das classes populares na comunidade nacional, se apoiou bastante na valorização das culturas regionais, insistindo no seu lugar valorizado, mas subordinado à cultura nacional. Essa fase se efetuou na França no último quarto do século XIX, onde coincidiram a obra escolar da III República e a famosa "idade de ouro" da imprensa, durante a qual a imprensa regional conheceu um crescimento notável.

É a esse processo que alude o programa de pesquisa proposto por Gustave Lanson (LANSON, 1965, p. 86):

[Dever-se-ia] mostrar o papel literário dos jornais, quer dizer não somente a parte consagrada à literatura nos jornais, mas também a repercussão do desenvolvimento da imprensa periódica na literatura, a substituição parcial e, em muitos lugares total, da revista e do jornal pelo livro; a ligação aqui e acolá da restauração das literaturas provinciais a uma imprensa possante animada de um vivo espírito regional7.

7 Comunicação feita por Gustave Lanson no dia 7 de fevereiro de 1903 na Sociedade de História Moderna sob o título "Idées de quelques travaux historiques à faire sur la littérature française". Primeira publicação em Revue d'histoire moderne et contemporaine, tome IV, 1903. Reproduzida em: Lanson, Gustave. Essais de méthode, de critique et d'histoire de la vie littéraire. Textes rassemblés et présentés par Henri Peyre, Paris, Hachette, 1965, p. 86. 
Esse projeto foi exposto em 1903 pelo pai fundador da história literária francesa. “É realizável?”, perguntava Lanson à Sociedade de História Moderna, diante da qual ele o apresentava. Um século depois, o desafio ainda merece ser relançado.

\section{REFERÊNCIAS BIBLIOGRÁFICAS}

Anderson, Benedict. Imagined Communities, Reflection on The Origin and Spread of Nationalism. Londres: Verso, 1983.

Baumgarten, Jean. Le Yiddish. Paris: PUF, 1990.

BERNARD, Antonia. La langue slovène au xixe siècle: processus d'élaboration de la langue littéraire et "slovenski preporod" (1760-1867). Tese. Institut National des Langues et Civilisations Orientales, Paris, 1998.

Dieckhoff, Alain. L'Invention d'une nation. Israël et la modernité politique. Paris:

Gallimard, 1993.

GELLNER, Ernest. Nations and nationalism. Londres: Oxford, 1983.

Habermas, Jürgen. L'Espace public. Paris: Payot, 1978.

Karniel, Zvi. The Feuilleton. Popular Writing leads to National Literature. Anais do

Colóquio internacional Trames, Littérature populaire, peuple, nation, région, Limoges: Faculté des Lettres et des Sciences Humaines, p. 249-252, 1986.

Lanson, Gustave. Essais de méthode, de critique et d'histoire de la vie littéraire. Textes rassemblés et présentés par Henri Peyre. Paris: Hachette, 1965.

QUÉFFELEC, Lise. La Querelle du roman-feuilleton, Littérature, presse et politique, un débat précurseur, 1836-1848. Grenoble: Ellug, 2000.

Robin, Régine. L'Amour du yiddish. Paris: Éditions Sorbier, 1984.

Thiesse, Anne-Marie. La Création des identités nationales, Europe XVIII-XX siècle. Paris: Seuil, 1999.

Recebido: 26/02/2020 | Aprovado: 09/08/2020 